
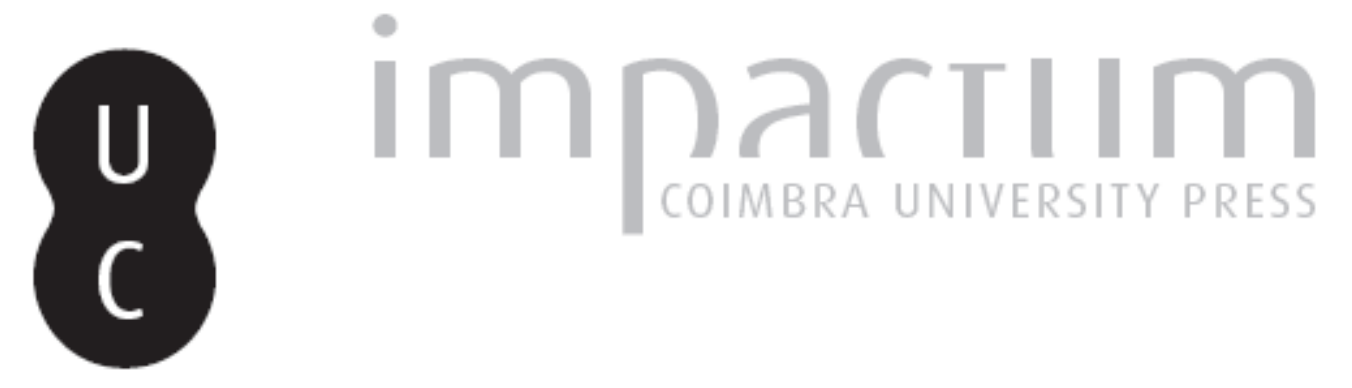

Notas sobre o publicismo liberal: o discurso de Marino Miguel Franzini: geógrafo e
metereologista

Autor(es): $\quad$ Nunes, Maria de Fátima

Publicado por: Imprensa da Universidade de Coimbra

URL

persistente:

URI:http://hdl.handle.net/10316.2/43774

DOI:

DOI:https://doi.org/10.14195/2183-8925_10_15

Accessed : $\quad$ 26-Apr-2023 16:36:43

A navegação consulta e descarregamento dos títulos inseridos nas Bibliotecas Digitais UC Digitalis, UC Pombalina e UC Impactum, pressupõem a aceitação plena e sem reservas dos Termos e Condições de Uso destas Bibliotecas Digitais, disponíveis em https://digitalis.uc.pt/pt-pt/termos.

Conforme exposto nos referidos Termos e Condições de Uso, o descarregamento de títulos de acesso restrito requer uma licença válida de autorização devendo o utilizador aceder ao(s) documento(s) a partir de um endereço de IP da instituição detentora da supramencionada licença.

Ao utilizador é apenas permitido o descarregamento para uso pessoal, pelo que o emprego do(s) título(s) descarregado(s) para outro fim, designadamente comercial, carece de autorização do respetivo autor ou editor da obra.

Na medida em que todas as obras da UC Digitalis se encontram protegidas pelo Código do Direito de Autor e Direitos Conexos e demais legislação aplicável, toda a cópia, parcial ou total, deste documento, nos casos em que é legalmente admitida, deverá conter ou fazer-se acompanhar por este aviso.

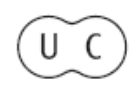


REVISTA DE HISTORIA DAS IDEIAS IO
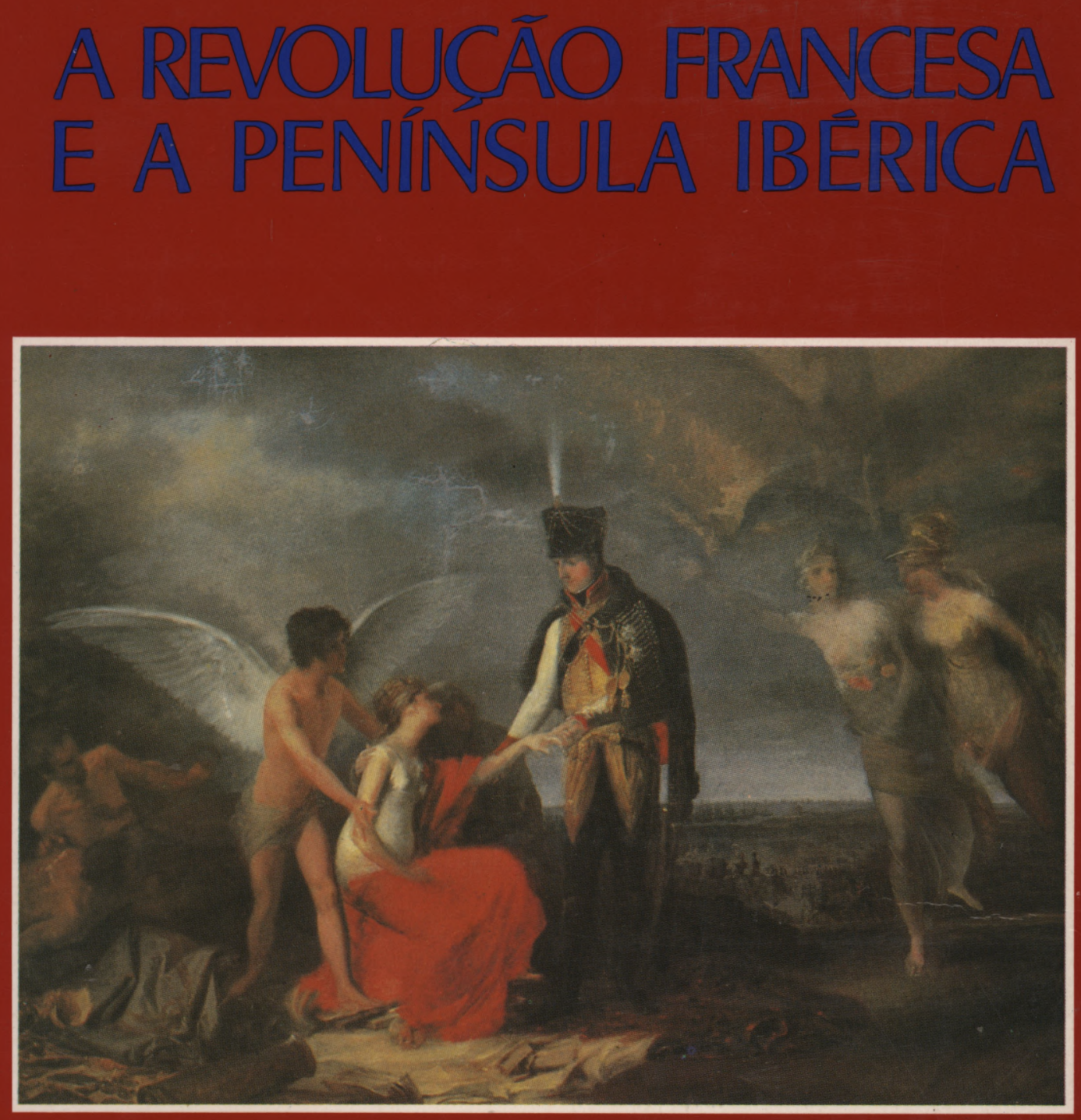

INSTITUTO DE HISTÖRIA E TEORIA DAS IDEIAS FACULDADE DE LETRAS 
MARIA DE FATIMA NUNES *

\title{
NOTAS SOBRE O PUBLICISMO LIBERAL: O DISCURSO DE MARINO MIGUEL FRANZINI - GEÓGRAFO E METEREOLOGISTA
}

\begin{abstract}
«Et pourtant, que de raisons de remettre en lumière le groupe des Idéologues. A le négliger, on risque en effet de méconnaître la source d'une grande part des sentiments et des manières de penser de nos contemporains. Ces philosophes apparaissent comme les intermédiaires nécessaires entre l'Ancien Régime et la France d'aujourd'hui: rarement la notion de géneration s'appliqua de façon plus nette qu'a levr groupe.... Politiquement, les Idéologues ont inspiré ce qui dans l'oeuvre de la Révolution, devait être le plus durable».
\end{abstract}

Jean Gaulmier, L'Idéologue Volney

Paris, 1951.

\section{Franzini no magistério pedagógico dos Ideólogos}

Franzini encontra-se vivencialmente na encruzilhada do Iluminismo para o Liberalismo ( ${ }^{1}$ ). Duplo filho das Luzes pombalinas e da renovação pedagógica e científica introduzida em Portugal, com a promulgação dos Estatutos da Universidade de

* Centro de História da Cultura da U.N.L.

(1) Filho de Miguel Franzini, lente de matemática da Universidade de Coimbra, chamado a Portugal juntamente com outros italianos, trazendo algumas repercussões do iluminismo italiano e o novo padrão cultural e científico, da Europa setecentista. Marino Miguel Franzini, que fez os seus estudos curriculares na Academia da Marinha e na Academia dos Guardas Marinhas, distinguiu-se pela acção técnico-científica e pelo sey saber pragmático e utilitário, nos domínios da geografia e das finanças. Sobre a acção e o pensamento de Marino Miguel Franzini (1800-1860) veja-se a nossa dissertacão de Mestrado, apresentada no Mestrado em História Cultural e Política, na F.C.S.H., da U.N.L. 


\section{Revista de História das Ideias}

Coimbra, teve um papel activo no publicitar dos novos, ou renovados, conhecimentos científicos, pragmáticos, utilitários e constitutivos da optimização racionalista da «felicidade pública», do «bem dos Povos» e «regenerar das forças do Estado». Marino Miguel situa-se entre dois grandes paradigmas existenciais, e cognitivos, setecentistas - as Luzes e a Revolução Francesa, diversificados em múltiplos vectores de intervenção e desdobrados em várias matrizes referenciais. Um e outro movimento, de carácter político, social e cultural, com nítidas repercussões económicas na esteira dos magistérios pedagógicos difundidos, criaram, em toda a Europa, ecos de mimetismo, adequado, ou possibilitado, pelos condicionalismos locais e pelas diferentes conjunturas e vicissitudes nacionais, do final do século XVIII para o dealbar do XIX. Afinal, ponte de ligação, temática e cronológica, entre Iluminismo/Liberalismo, que criaram, ou possibilitaram, perfis individuais idiossincráticos. Das Luzes sairam vectores onomásticos, bibliográficos, ideológicos e mentais que viriam a ser os alicerces estruturais da ideologia liberal, num Cosmos humanizado e libertado de dogmas inexplicáveis, dimensionado para a sociedade a construir, ou a sonhar utopicamente, sob o estigma da perfectibilidade, mas também da liberdade, do individual e da felicidade, da propriedade e do utilitarismo dos bens individuais, somatório que axiomatiza e constrói o (novo) Estado, qualitativamente liberal e jusnaturalista.

Foi neste Espaço e Tempo de teor cultural, concretamente acelerado e rasgado pela Revolução Liberal de 1820, que Marino Miguel Franzini actuou e se revelou como um homem pragmático, detentor de um potencial de saber técnico, que várias vezes lhe permitiu, e possibilitou, o acesso ao poder, ideologicamente marcado pelas traves mestras do liberalismo. Sob o rótulo da competência e do prestígio científico Franzini soube, e conseguiu plenamente, galvanizar o interesse dos seus contemporâneos, que, unanimemente, lhe reconheceram facetas inovadoras e um perfil intervencionista diferente nos domínios políticos e culturais da primeira metade do século XIX português.

Das referências colhidas destaca-se o acordo discursivo, referências múltiplas que vão desde «o mais antigo, curioso e constante metereológico português.... geógrafo, estatístico.... integérrimo e ilustrado» $\left({ }^{2}\right)$, a enunciados como este:

(2) Feliciano Castilho, Memórias de Castilho, 2.: ed., t. V, Coimbra, Imprensa da Universidade, 1932, p. 149. 


\title{
O Discurso de Marino Miguel Franzini
}

\begin{abstract}
«Estamos certos, que os nossos leitores se lisongearão connosco. de ver aqui publicado o mapa.... de observações metereológicas.... Escusamos de dizer alguma coisa sobre a sua exactidão por quanto o nome do sr. Marino Miguel Franzini tão bem conhecido pelos seus interessantes trabalhos desta natureza, é quanto basta para no-los garantir» (3).
\end{abstract}

E sem receio que afirmamos que M.M. Franzini funcionou como símbolo do utilitarismo da ciência, face às vivências reais da sociedade, desenvolvendo o seu saber, de teor científico, mediatizado pela técnica, em função das necessidades e realidades existentes, fundamentalmente em três grandes domínios materiais da sociedade-agricultura, manufacturas e o comércio, áreas que ocupam um lugar de destaque, no plano das materializações, no ideário, e imaginário, do utilitarismo liberal.

$\mathrm{Na}$ esteira publicista dos Ideólogos (Condorcet, Volney, Destut-de-Tracy)..., que por sua vez se perfilam nos meandros do enciclopedismo iluminista, pretende-se ver nas diferentes etapas do publicismo 'franziniano' alguns ecos da junção da teoria científica com a praxis real e existencial, fazendo despertar múltiplas apetências e inovações experimentais, formando-se condições favoráveis à prossecução da modernidade cultural e material.

Concretamente pretende-se com a acção do publicismo científico (enraizado em determinados padrões e acontecimentos epocais) tornar de abordagem acessível, e inteligível, as transformações possibilitadas pela junção da matemática com a física, vocacionando a Ciência para um saber técnico, prático, útil e pragmático, mas também profundamente humano e humanizante. No caso em análise, verificámos que é a área do conhecimento geográfico $\left(^{4}\right)$ que favorece e torma possível, muitas p. 177.

(3) Jornal das Sciencias Médicas de Lisboa, t. I, Janeiro, 1835,

(4) Trata-se do novo conhecimento geográfico advindo da revoJ:ção cultural dos Ideólogos, das suas observações, viagens, espírito racionalista, vocacionados para os interesses individuais de um grupo social em ascensão material - a burguesia. Geografia, ponto de vista pedagógico e didáctico, considerada como área do conhecimento que englobava os aspectos físicos mas também os aspectos humanos, uma vez que «desde el siglo XVIII la geografía se identificó crecientemente.... con la descripción de países. Algunas definiciones dadas en el siglo XIX destacaban precisamente este rasgo y lo convertían esencial». Geografia que comportava três divisões fundamentais: astronomia, física e política, mas que adquiriu, simultaneamente, um cariz publicista - «La geografia tenía también una utilidad extrema para el conocimiento del propio país. Los interesses nacionalistas de la burguesía de la epoca encontraban en la ciencia geografica un canal de trans- 
vezes, estabelecer a ponte de ligação entre os ensinamentos apreendidos no âmbito curricular da Academia dos Guardas Marinhas e os vectores ideológicos, de pendor liberalizante, advindos do contacto pedagógico do novo saber epistemológico, com a sociedade portuguesa e a moldagem da sua estrutura cultural.

A divulgação científica, para chegar a um amplo público e possuir um estatuto político, tinha de agarrar problemas concretcs e necessidades de todos conhecidas, visualizar a conjuntura, de crise, em que assentavam as vivências quotidianas, prosaicas e individuais do Estado, quer no período pré-liberal, quer no período pós vintismo. É neste sentido que Franzini publicita que «o Naturalista poderá abrir à Indústria, e ao Comércio, novos mananciais de riqueza. Fábricas de ferro, de alumen e caparosa; manufacturas de porcelana, e de vidros; melhoramentos nas fábricas de loiça.... dariam aos habitantes uma actividade desconhecida, fornecendo-lhes meios de enriquecerem» $\left({ }^{5}\right)$.

Franzini publicista vs. Franzini com potencialidades abertamente liberais, detentor e utilizador hábil de um universo lexical, programaticamente vulgarizador, onde se situam signos como os de riqueza, indústria, fábrica, melhoramentos, enriquecer, comércio, felicidade, a partir dos quais se pode efectuar uma verdadeira acção publicista, dimensionando-lhe novos conteúdos

m.isión importantísimo.... Pero también ayudava a las ansias de regeneracion social y económica que se difundían por todo el país despues de la Guerra de la Independência, y que no era más que una herencia del periodo final de la Ilustracion", Ciencia para la Burguesia, Barcelona, Universita de Barcelona, 1983, pp. 131 e 136 respectivamente.

Cf. Marino Miguel Franzini, Instrucções statisticas que por ordem do Ex.mo e Rev.mo Sr. Principal Sousa, compilou MMF, agregado à Brigada Real da Marinha em 1814, Lisboa, Imp. Régia, 1815, onde é muito visível o paralelismo enunciado para o contexto espanhol.

Ainda no âmbito do alargamento epistemológico da geografia como elo de ligação e transmissão da Ilustração para o Liberalismo, cf. Sergio Moravia, "I viaggi come scienza e la scienza dell'uomo», in La scienza dell'uomo nel settecento, Roma, ed. Laterza, 1978, p. 151 e ss.; Georges Gusdorf, Les sciences humaines et la pensée occidentale VIIIla conscience révolutionnaire. Les Idéologues, Paris, ed. Payot, 1978, especialmente o capítulo "Les Idéologues et la révolution culturelle», p. 307 e ss.

(5) Instrucções Statisticas, p. 14. Estas Instrucções constitvem a divulgacão publicista, racional e científica, dos conhecimentos 'statisticos' já postos em práticas nas "nações cultas e iluminadas», devidamente adaptadas ao "patriotismo» nacional, necessário em 1814, para se proceder ao real e dinâmico conhecimento das potencialidades do Reino a fim de os seus "cidadãos» poderem usufruir da "felicidade pública». 


\section{O Discursolde Marino Miguel Franzini}

e possibilidades, desvendando cientificamente potencialidades que a todos interessam e que podem traduzir o somatório racionalista da Felicidade e da Liberdade, numa asserção dinâmica e vocacionada para um tempo futuro, um regenerador devir construtivo.

Como método, ou meio de atingir tais objectivos, utiliza-se a viagem, real ou idealizada, a observação, a anotação, o registo, a análise e a síntese da realidade matematizável, transformável, num esforço de transmudar a Natureza física e os Homens, ou seja a sociedade, o Estado e seus respectivos organismos constitutivos. $\mathrm{P} \epsilon$ gando nas duas facetas mais vincadamente publicistas, a gengrafia, no âmbito particular da cartografia, e a metereologia, é visível discernir de que modo Franzini soube interiorizar canais de influências, aprender, e sobretudo, apreender vectores culturais, tendencialmente ideológicos e passíveis de alterações políticas, de acordo com o seu tempo histórico. Por detrás do seu discurso de competência, contagens e anotações matemáticas e rigorosas está claramente espelhado um outro discurso, onde o saber é amplamente divulgado e publicitado, conferindo-lhe a essência mediatizadora entre o saber e o ensinar, o teorizar e o divulgar.

\section{Opinião pública e acção publicista}

A acção publicista de Marino Miguel Franzini consubstanciou-se na publicação dos seus estudos e observacões matematizáveis da realidade existente ou com potencialidades para... O impacto dava-se ao nível das tonalidades do discurso científico emitido e dos complexos discursivos $\left(^{6}\right)$ utilizados e manejados, quer antes, quer depois da data paradigmática de 1820. Como nota comum a todos os escritos encontramos a publicitação das antinomias componentes da ideologia liberal ( $\left.{ }^{7}\right)$.

«Assim como um particular não pode melhorar os seus bens, e aumentar a sua riqueza, sem conhecer exactamente, a extensão das suas terras, a qualidade do solo, as plantas que mais lhe convém, o melhor método de as cultivar, etc., também os Governos nunca poderão melhorar o estado de um país, e a condição dos seus habitantes, sem entrarem nos exames os mais extensos, e laboriosos

${ }^{(6)}$ Cf. Patrick Tort, La pensée hiérarchique et l'évolution, Paris, ed. Aubier, 1983, especialmente o capítulo "Les complexes discursifs et le concept d'ouverture logique», pp. 43-57.

$\left.{ }^{7}\right) \mathrm{Cf}$. André Vachet, L'Idéologie Libérale. Individu et sa pro. prieté, Paris, ed. Anthropos. 1970. 
desta natureza, a fim de conhecerem, e poderem remover os obstáculos, que se opõem à felicidade pública»

(Instruções Statísticas - 1814)

«As observações metereológicas que têm por objecto determinar as qualidades características dos diversos climas do globo terrestre, são da maior importância para os habitantes dos mesmos sítios, pela sua imediata aplicação à agricultura, navegação, medicina e higiene, pois que nos servem para regular os diversos trabalhos com probabilidade de bom êxito"

(Observações acerca das chuvas que cairam em Lisboa -1859).

- Dois excertos tematicamente diferentes e distanciados no tempo, mas com um elo invisível de ligação: a publicitação de ideias directamente vocacionadas a sensibilizar, pela força do rigor e da competência incontestável da Ciência, a opinião pública, quer o comum leitor que passeava os olhos pelos hebdomadários de conhecimentos úteis e variados, quer das elites institucionalizadas do poder, quer ainda de toda uma camada social ávida de construir um outro modus vivendi axiomatizado pelo progresso, pela esperança e pelo modelo da perfectibilidade optimista, traduzida no ccnceito, alargado, de propriedade pública e individualmente alienável.

\section{Cartografia}

Em 1811 Investigador Portuguez em Inglaterra dá-nos a seguinte noticia:

«Temos o prazer de anunciar ao público a Carta Hydrographica da Costa de Portugal, que Mr. Arrowsmith está gravando em Londres, composta por Marino Miguel Franzini, major do Real Corpo de Engenheiros, cuja obra é a mais perfeita que neste género se tem até agora publicado» $\left(^{(8)}\right.$.

E o mesmo jornal que nos dá o título completo da obra em questão - Carta reduzida da Costa do Reino de Portugal desde o Cabo Silleira athe a barra de Huelba, ajustadas as observações astronómicas, e trigonométricas, executadas em diferentes epochas no sobredito Reino - offerecida a S.A.R. o Principe Regente N.S. por intervenção do Illmo. Exmo. Conde de Linhares, Ministro e Secretário de Estado dos Negócios Estrangeiros e da

(8) O Investigador Portuguez em Inglaterra ou Jornal Literário e Político, n.o 4, Out. 1811, p. 653. 


\section{O Discurso de Marino Miguel Franzini}

Guerra - sendo ordenado, e auxiliado este trabalho pelo Exmo. Jorge Crawfield Barkeley, Almirante das Esquadras de S.M.B. e das Esquadras de S.A.R. o Principe Regente N.S. - e construída pelo Major do Real Corpo de Engenheiros - Marino Miguel Franzini, 1811.

Como o próprio título indica trata-se de uma compilação /síntese dos trabalhos congéneres já anteriormente efectuados, a que se deram algumas actualizações, e que Franzini envia para Londres.

"O desejo que sempre tive de ser de alguma utilidade fez com que empregasse os momentos que me restava das diferentes comissões de serviço, em que tenho sido empregado no objecto de recolher materiais e observações com que pudesse algum dia redigir uma boa Carta do Reino de Portugal, a qual finalmente fizesse esquecer todas as que os estrangeiros tem publicado até ao presente, cheias de erros e deformidades.... O Almirante Barkeley.... mostrou os maiores desejos que eu me ocupasse com a Carta hydrographica da nossa costa, da qual não existe até ao presente mais do que a Carta que o célebre Tofino publicou no seu magnífico Atlas.

V. Ex." sabe muito bem que os ciúmes políticos embaraçaram que ele prolongasse as suas operações sobre a costa de Portugal, sobre a qual se demorou muito poucos dias, resultando daí que o seu trabalho apesar de ser o melhor que até ao presente tem aparecido, e com tudo cheio de erros, pois nas latitudes da costa do Minho há diferença até de 9 minutos ou 6 léguas, com as verdadeiras latitudes determinadas pelas excelentes observações astronómicas de Ciera. Isto mesmo o confessa o chefe de Esquadra D. José Espinoza na excelente obra que publicou em 1809 intitulada Memorias sobre las observaciones astronomicas hechas por los Navegantes Espanholes en destinados lugares del globo, las quales han servido de fundamento para la formacion de las Cartas de Marear, publicadas por la Direccion de trabajos hydrographicos de Madrid, 2 vols.....» $\left({ }^{\vartheta}\right)$.

Se é fácil constatar as preocupações utilitárias expostas não é menos interessante apontar alguns dos muitos conselhos pormenorizados enviados em 1811 por Franzini para o geógrafo londrino Arrowsmith, "Geógrafo de S.M.B., morador em Soho Square n. ${ }^{\circ}$ 10». Todos os detalhes são anotados, desde os reparos ortográficos, passando pelos cuidados a ter com a edição bilingue de uma memória até à elegância e precisão do trabalho final com uma explanada, e prolongada, explicação de todo o trabalho

( $\left.{ }^{9}\right)$ Idem, ibidem, pp. 654-656. 
realizado ao nível da medições, triangulações... $\mathrm{E}$ é com empenho que assegura:

«Entrei nesta discussão para vos dar uma ideia da exactidão do trabalho que ides publicar. Os detalhes da Costa são extraídos dos meus trabalhos particulares, e das cartas particulares excelentes, desconhecidas inteiramente do público. A minha Carta contém 400 nomes de vilas, aldeias, cabos, rios, etc. e 640 sondas, não compreendendo a parte da Costa de Espanha contida na mesma carta. A de Mr. Tofino contém só 107 nomes e 80 sondas.

De tudo isto resulta uma obra inteiramente nova, que espero seja acolhida favoravelmente pelo público, qye ama o aperfeicoamento da hidrografia e servirá de suplemento à soberba obra de Tofino. A colecção preciosa das sondas me tem sido fornecida pelas ordens de S. Ex." o Almirante Berkeley que mandou ao longo da Costa fazer este importante trabalho» $\left({ }^{10}\right)$.

Após esta longa e demorada permanência em torno da Carta Hydrographica de 1811 é fácil depreender a sua ligação com as duas cbras de Franzini, enquanto cartógrafo, de maior divulgação; o Roteiro e a Carta, que lenta, mas progressivamente, cresceram nas mãos e no pensamento de Franzini.

Roteiro das Costas de Portugal, ou Instrucções náuticas para intelligencia e uso da carta reduzida da mesma costa, e dos planos particulares dos seus principais portos, dedicado a Sua Alteza Real o Principe Regente Nosso Senhor por Marino Miguel Franzini. major do Real Corpo de Engenheiros, Lisboa, ed. Imprensa Régia, 1812.

Carta marítima da costa de Portugal, composta de três folhas em papel de grande formato, gravado em Londres por Arrowsmith, à qual se ajunta um roteiro circunstanciado que não só descreve a costa com exacção, mas analysa o trabalho da mesma carta, Lisboa, 1813 (11).

Obviamente que estas duas publicações estão intimamente ligadas, e constituem o trabalho cartográfico de grande fôlego e de maior divulgação. Dois testemunhos publicistas, e científicos, que veicularam a figura de Franzini até aos nossos dias e que na época em que foram produzidos mereceram amplo destaque como o que é dado, em 1813, em O Investigador Portuguez

(10) Idem, ibidem.

(11) Referências textualmente extraídas do Diccionário Bibliográphico de Inocêncio, vol. VI (Marino Miguel Franzini); estes trabalhos encontram-se igualmente referidos na História dos Estabelecimentos Scientíficos em Portugal, tomo IV, p. 219. 
em Inglaterra ${ }^{\left({ }^{12}\right)}$ que dá conta da Carta Hydrographica e do Roteiro das Costas de Portugal dizendo que

"o habilissimo engenheiro português Marino Miguel Franzini, eficazmente auxiliado pelo vigilante e paternal governo de Portugal, e pelo Almirante Berkeley procurou corrigir tais erros e dar uma Carta Hydrographica e Roteiro exacto das Costas de Portugal; o que nos pareceu ter seguido depois de penosas observações, assíduo trabalho, e do mais louvável zelo pelo serviço de S.A.R., o Principe Regente».

Contudo, o génio e labor de Franzini rompeu e ultrapassou o espaço temporal e geográfico da Península. A 5 de Agosto de 1816 foi lido na Academia Real das Ciências de Paris, um Rapport de M. Buach relativo ao Roteiro das Costas de Portugal, concluindo que
«o sr. Franzini reuniu em uma tabuada comparativa as latitudes e longitudes de todos os pontos da costa de que se serviu, e a diferença destas determinações a respeito daquelas que se acham nas Efemérides de Coimbra, o conhecimento dos tempos, e o Roteiro Portuguez de Pimen- tel.... Seria difícil fazer extractos de uma tão concisa, e tão metódica como é o Roteiro do sr. Franzini sem lhe fazer perder uma parte do seu merecimento» (13).

M.M. Franzini publicitou e aplicou pragmática e orientadamente os seus conhecimentos geográficos, advindos das suas vıagens e do espírito científico da observação e do registo, mas também conseguiu galvanizar a acção publicista em seu favor, grangeando-lhe reputação e prestígio dentro e fora das fronteiras peninsulares, sempre impulsionado pela vontade de ser útil e melhorar os conhecimentos geográficos, pondo-os à disposição de todos, com elevado grau de confiança e perfectibilidade no plano da vanguarda e do avanço das «Nações cultas da Europa» que

«têm empreendido grandes e dispendiosas expedições para procurarem à segurança da Navegação, este indispensável auxílio, não se limitando somente aos seus próprios domínios, mas até empreendendo dilatadas viagens aos pontos mais distantes do Mundo, a fim de aperfeiçoar cada vez mais os conhecimentos hidrograficos» (14).

(12) O Investigador Portuguez, n. 30, Dez. 1813, pp. 249-250.

(13) Jornal de Coimbra, n..$^{\circ}$ LII, parte I, 1817, pp. 269-272.

(14) Marino Miguel Franzini, Roteiro das Costas de Portugal, p. 5. 


\section{Revista de História das Ideias}

\section{Metereologia}

É, sem dúvida, nas várias dezenas de observações metereológicas que a faceta do publicismo surge com maior dimensão, estabelecendo uma ligação escrita, e divulgadora, entre um renovado saber científico e os conhecimentos úteis, necessários para a construção do progresso, prometaico, inerente ao Liberalismo. A metereologia adquiriu através do discurso de Franzini um carácter humanizante e eminentemente utilitário, elemento indispensável ao Homem e à fruição material das forças da Natureza. Apenas se tornava necessário conhecê-la, estudá-la e divulgá-la, porque

"contra a aparência que oferecem à primeira vista, nas nossas regiões, os fenómenos atmosféricos, os quais entregues à confusão e desordem, existem realmente leis que nos seria útil conhecer, e que só unicamente a observação nos poderá fazer descobrir» (15).

Desta observação meticulosa, e orientada para uma sensibilidade humana e pragmática, resultam sensíveis melhoramentos no âmbito da agricultura e da medicina, pois

«As observações metereológicas que tem objecto de determinar as qualidades características dos diversos climas do globo terrestre, são da maior importância para os habitantes dos mesmos sítios, pela sua imediata aplicação à agricultura, navegação, medicina e higienistas, pois que nos servem para regular os diversos trabalhos com probabilidade de bom êxito" (16).

É através de uma faceta enciclopédica, ao gosto das apetências eclécticas da opinião pública, que a acção publicista se

(15) M.M. Franzini. «Observações metereologicas feitas na cidade de Lisboa, no anno de 1816 e 1817, acompanhadas de varias reflexões sobre o estudo e aplicação da metereologia, offerecidas à Real Academia das Sciencias", in História e Memórias da Academia Real das Sciencias de Lisboa, tomo V, parte I, 1817, p. 93.

No seguimento da explanação dos inúmeros benefícios da metereologia Franzini refere-se às instituições científicas europeias que desenvolvem trabalhos semelhantes ao seu labor individual como a Sociedade de Medicina de Paris, a Academia das Ciências de Paris, a Sociedade de Metereologia de Manheim, de que Franzini era sócio correspondente.

(16) M.M. Franzini, Observações acerca das chuvas que caíram em Lisboa segundo as séries abaixo transcritas, 23 Fev., 1859, 1 folha, s/ed. 


\section{O Discurso de Marino Miguel Franzini}

exerce $\left({ }^{17}\right)$, demonstrando matematicamente a utilidade de um compartimento da ciência - neste caso a metereologia - para o progresso e melhoramento de domínios da sociedade, que, invisivelmente, dependem de uma correcta articulação entre o saber, o poder e a divulgação pedagógica. E Franzini não deixa, mais uma vez, de utilizar, no reforço da sua argumentação, as «Nações cultas», onde se têm multiplicado as observações metereológicas, sob orientação, e conta, dos Governos.

Contudo, os seus artigos assumiram ainda outras finalidades. Num campo mais particular e pragmático as observações metereológicas adquiriram quase um estatuto de intervenção cultural, no país e no tempo em que foram produzidas. Vejamos de que modo, e em que sectores.

Reparemos que as «notícias agronómicas» que acompanham geralmente as observações metereológicas constituem um pequeno campo de amostragem do que a nível geral, de todo o país, seria possível efectuar. Observa-se a agricultura com um olhar perspicaz e científico, obtendo-se a resposta para um pressuposto inquérito:

«As aparências dos campos no termo de Lisboa oferecem notáveis fases, segundo as variadas vicissitudes atmosféricas deste mês. Em muitos sítios foram fatais à vegetação os ventos furiosos do Norte e do Noroestes, da terceira quadra de Julho, os quais queimaram muitas árvores e as hortaliças.... prejudicaram notavelmente os milhos semeados em terrenos elevados.... As oliveiras não obstante terem perdido a maior parte dos frutos de que se achavam sobrecarregadas, prometem ainda abundante colheita, principalmente nos grandes olivais que aformoseavam as margens do Tejo até Abrantes. As vinhas oferecem geralmente um

(17) Baseamo-nos nos inúmeros artigos publicados quer na Revista Universal Lisbonense quer em O Panorama. Repare-se no enunciado dos títulos que evidenciam abertamente os objectivos pretendidos: «Metereologia. Utilidade e progresso da sciencia - das trovoadas e do raio - preocupações acerca deste phenomeno" (O Panorama, vol. I, n. 12, 22 Julho 1837, p. 92); "Reflexões sobre as influências das estações na mortalidade dos habitantes de Lisboa» (R.U.L., n. 42,21 Julho, 1842, pp. 494-95); "Metereologia. Observações sobre a quantidade de chuva anual em Lisboa, comparada à de outros pontos do globo" ( $O$ Panorama, vol. II, n. ${ }^{\circ}$ 48, 31 Março 1838, p. 99); "Reflexões sobre a influência das estações na mortalidade dos habitantes de Lisboa» (R.U.L., n.o 42, 21 Julho 1842, pp. 493-494).

Por outro lado os simples «resumos das observações metereológicas» feitos na cidade de Lisboa, para vários anos, durante os doze meses do ano, vinham sempre acompanhados de comentários esclarecedores da utilidade desta ciência. 
notável fenómeno na sua frutificação, aparecendo nos mesmos cachos bagos perfeitamente sazonados a par de outros ainda verdes e carbonizados...» (18).

E desta observação dos fenómenos naturais, e respectiva interpretação técnica e científica, que se pode promover o desenvolvimento e a prosperidade, como acontece na zona piloto de Mafra, «que tem tido notável incremento, com novos arroteamentos, variações de sementeiras, e criação de gados, no novo estabelecimento rural, que vai prosperando na real tapada, sustentado por Sua Magestade com esmero...» ( ${ }^{19}$ ).

Através do seu discurso publicista de conhecimentos úteis Franzini procura englobar o papel do poder, simbolizado na figura do rei, que deverá proteger e incentivar os trabalhos de observação científica, pois daí resultam os verdadeiros melhoramentos da regeneração liberal. Dentro desta perspectiva pragmática e utilitária da metereologia inserem-se as anotações feitas sobre «os pingos de chuva» caídos na capital e a sua potencial utilidade material, quando devidamente usada por um saber técnico e científico, vocacionado para o real e o concreto.

A saúde pública, ou seja as condições higiénicas e sanitárias da população, fazem parte do ideário metereológico de Franzini. As epidemias são um dos males maiores da mortalidade da população e

«não se pode duvidar que o benigno e saudável clima desta cidade se tem deteriorado com o andar dos tempos.... É portanto por analogia que deveremos presumir que também o nosso delta pútrido subterrâneo dos canos de esgoto de Lisboa, e o que especialmente abrange o litoral da capital, desde o Beato António até Alcântara e Belém, que aumenta anualmente, e tem feito inabordáveis todos os cais da cidade na baixa mar, o qual no recôncavo ou pequena baía, compreendida entre o cais das colunas e a ribeira de Alcântara, contém perto de dois milhões de metros cúbicos de lodo, ocuparia uma superfície igual à da praça do Comércio, tulhada de imundíceis, na altura de 180 palmos, sejam capazes de provocar a aparição das febres pulodosas de ruim carácter» $\left({ }^{20}\right)$.

(18) «Resumo das observações metereológicas feitas em Lisboa no mez de Setembro de 1843", R.U.L., n. 9 , 19 Out. 1843, pp. 106-107.

(19) "Resultado das observações metereológicas de 4 de Abril de 1844», R.U.L., n. 45,27 Junho 1844, p. 538.

(20) "Mappa do movimento necrologico de Lisboa e Belem comprehendendo o numero de cadaveres sepultados nos tres cemiterios, S. João, Prazeres e Ajuda, no anno de 1857», Diário do Governo, n. 44, 22 Fev. 1858. 
Dentro deste contexto porque não aproveitar a água da chuva para prover de água potável os habitantes da cidade de Lisboa, assim como rentabilizar a pluviosidade para «a canalização subterrânea, para conseguir a remoção das imundíces, as quais demoradas nos bairros da cidade baixa tanto influem na deterioração da saúde dos seus moradores» $\left({ }^{\mathbf{2 1}}\right)$.

A morte deixa de ser totalmente insuperável. Diríamos que nas observações metereológicas Franzini se posiciona face à possibilidade material de melhorar o meio físico em favor do Homem, cidadão de um Estado, mas também de um universo, e, paralelamente, encarava a morte como acontecimento abstracto, que poderia ser gerido e que tinha uma economia própria e distinta, uma nova antropologia económica e humana.

Por contraponto à morte, a vida terrena podia ser beneficiada, racionalmente, obtendo-se a desejável fruição da propriedade e dos interesses individuais inerentes ao Liberalismo. F. a acção publicista de M.M. Franzini, conotada com um papel de intervenção política e cultural, procurava abarcar duas direcções discursivas. Uma, a do poder institucionalizado, os liberais que davam rosto aos sucessivos governos e abstractamente representavam o Estado, figura cimeira dos ideários vigentes. Outra, a sociedade em geral, somatório de indivíduos tornados cidadãos, leitores, ou ouvintes, de O Panorama, da Revista Universal Lisbonense, do Diário do Governo ou mais selectamente das Memórias da Real Academia das Sciencias.

\section{Em conclusão}

No cenário da primeira etapa do liberalismo em Portugal M.M. Franzini é representativo de um perfil político actuante, modelado pelos axiomas da ciência e dos conhecimentos técnicos e úteis, distanciado dos palavrosos discursos oratórios que aqueciam o Parlamento e levavam ao rubro os debates governamentais. Dentro dos jogos de referências dos Ideólogos, também eles distanciados dos círculos universitários, políticos silenciosos de gabinete, Franzini conseguiu (de)monstrar, e tornar explícito, os seus princípios doutrinários e ideológicos, quer globalmente, quer conjunturalmente, mas procurando sempre fazer a adequação necessária entre o modelo aprendido e a realidade consta$r . \sin$

(21) «Comunicado» de M.M. Franzini, Diário do Governo, n. 59, 11 Março 1859. 
tada e passível de transformações técnicas e científicas, mas também, e por isso, revolucionárias.

Em termos de actuação política e pública Franzini, pela via publicista, soube evidenciar o papel do tecnocrata «avant la lettre» provando que para efectuar a "grande revolução», a «total regeneração» do país era tão importante efectuar medições trigonométricas, ou constatar as diferenças pluviométricas entre Sintra e Lisboa, como organizar, e debater na especialidáde, os orçamentos apresentados ao Parlamento. Metaforicamente, para a viabilidade do regime liberal, e a sobrevivência autónoma do Estado, era tão importante contar os votos liberais como as gotas de chuva durante o ano; divulgar os novos conhecimentos científicos e utilitários na imprensa era tarefa tão prioritária como combater jornalisticamente os miguelistas e todos os contra-revolucionários. 